ISSN: 2572-2964

\title{
Closed Reduction and Internal Fixation of Day II and III Crescent Fractures by Iliosacral Screw
}

\author{
Reda H. Elkady ${ }^{1}$, Hamed Abuelkhair, MD' ${ }^{2}$, and Sherif El-Aidy MD ${ }^{3}$ \\ ${ }^{1}$ Assistant professor of orthopedic surgery, Zagazig University, Egypt. \\ ${ }^{2}$ Lecturer of orthopedic surgery, Zagazig University, Egypt. \\ ${ }^{3}$ Lecturer of orthopedic surgery, Zagazig University, Egypt.
}

Abstract:

Background: Crescent fracture is defined disruption of part of the sacroiliac joint completed as a fracture iliac wing posteriorly. It can be fixed by a variety of methods. Closed reduction and iliosacral screw fixation can provide adequate stabilization in certain cases of crescent fractures.

Patients And Methods: The clinical study was aim at evaluating the clinical outcomes and functional scores of 30 patients (22 male and 8 female patients) aging from 28 to 54 years old. This study included 30 patients with LC fractures of pelvis and had been operated between April 2000 and June 2010. Plain X ray and CT of the pelvis were done for all cases. Day's classification and exclusion of dysmorphic sacra were done. Percutaneous IS was used in all patients who were selected as Day type II and III. The average follow-up period was 14 months (range: 12-21 months). The principal goal of surgical intervention was the accurate and stable reduction of the sacroiliac joint.

Results: There was minimal blood loss in all cases. The clinical outcome was good in all patients; there were no healing complications, postoperative neurological deficits, or residual rotational malalignment of the limb. Using Majeed scoring system for functional assessment; Mean score of the 30 cases was 87 points (55-100 points); 20 (66.5\%) patients had greater than 85 points (excellent), 9 (30\%) patients had 65-84 points (good), and one (5.5\%) patients 52 and 64 points (poor).

Discussion and conclusion: Percutaneous IS screw fixation is a valuable option in treatment of types II and III crescent fractures, with almost no blood loss and short intraoperative duration. The functional results of the patients treated by IS was good in average.

Level of evidence: The level of evidence was IV (case series).

Key words: Crescent, Iliosacral Screws, Lc Fractures, Sacroiliac Fracture Dislocations

\section{INTRODUCTION}

LC pelvic fractures make up to $80 \%$ of the pelvic ring injuries. rescent fractures are considered a less common subtype,although the exact percentage is difficult to estimate from the literature [1,2] Crescent fracture-dislocations form a characterized subset of the pelvic ring injuries resulting from an LC trauma. These fractures are characterized by incomplete disruption of the SI joint and extending proximally as a fracture of the ilium. Day et al. classified three types of these fractures according to the extent of sacroiliac joint extent. Type I is defined by having a large crescent fragment and the joint dislocation comprises less than one-third of the joint,. Type II fractures have intermediate-size crescent fragment and the dislocation forms between one-third and two-thirds of the joint. Type III fractures have a small crescent fragment in which the dislocation comprises more than two thirds of the joint but not the entire joint ([Figure 1]) [3]. 

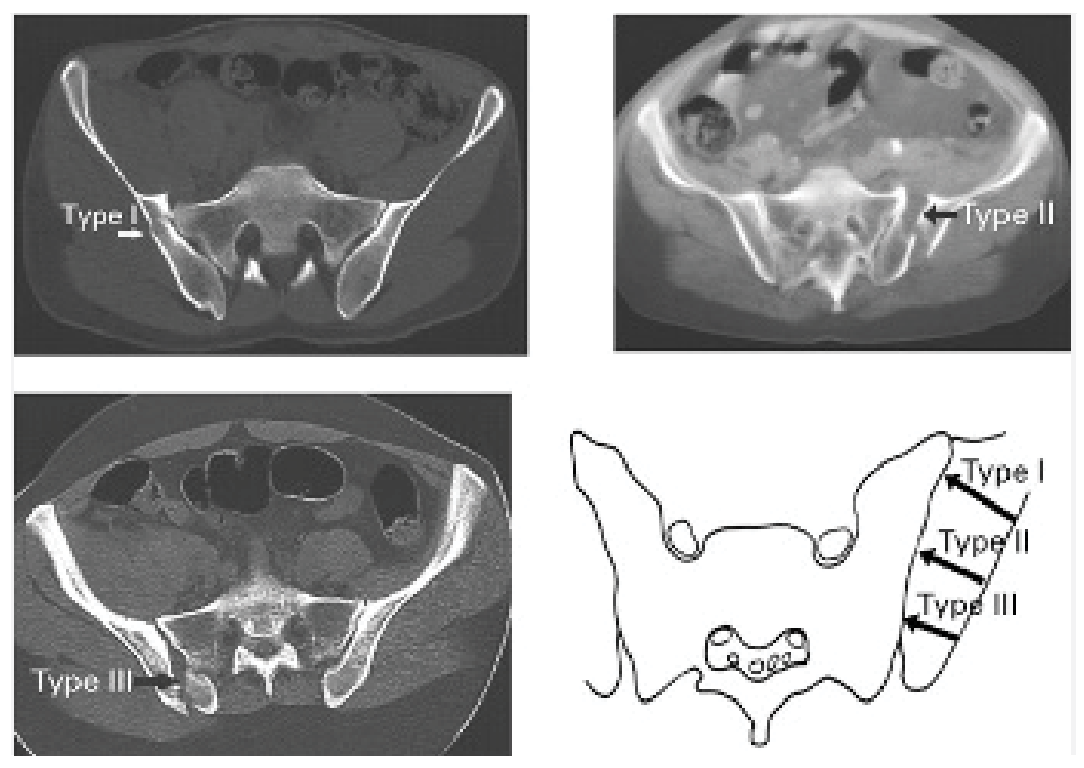

Figure 1 Different types of crescent fractures according to Day et al. [3].

The iliosacral articulation is considered a weight bearing joint [4] that can be affected by chronic instability, posttraumatic arthritis or malunion with the subsequent pain if not managed appropriately. The rate of back pain and difficulty to do light work in untreated cases compared to those who had surgery is high. Reestablishing the joint congruence and stabilizing it is important to minimize painful sequelae; hence, ORIF of iliosacral disruptions is necessary, apart from those cases having an acceptable joint reduction achieved by closed techniques [5].

In this study, good portion of outer iliac table remains sufficient in Day type II and type III ([Figure 2] and [Figure 3]) at the site of screw insertion, the IS is used and provides stable fixation.

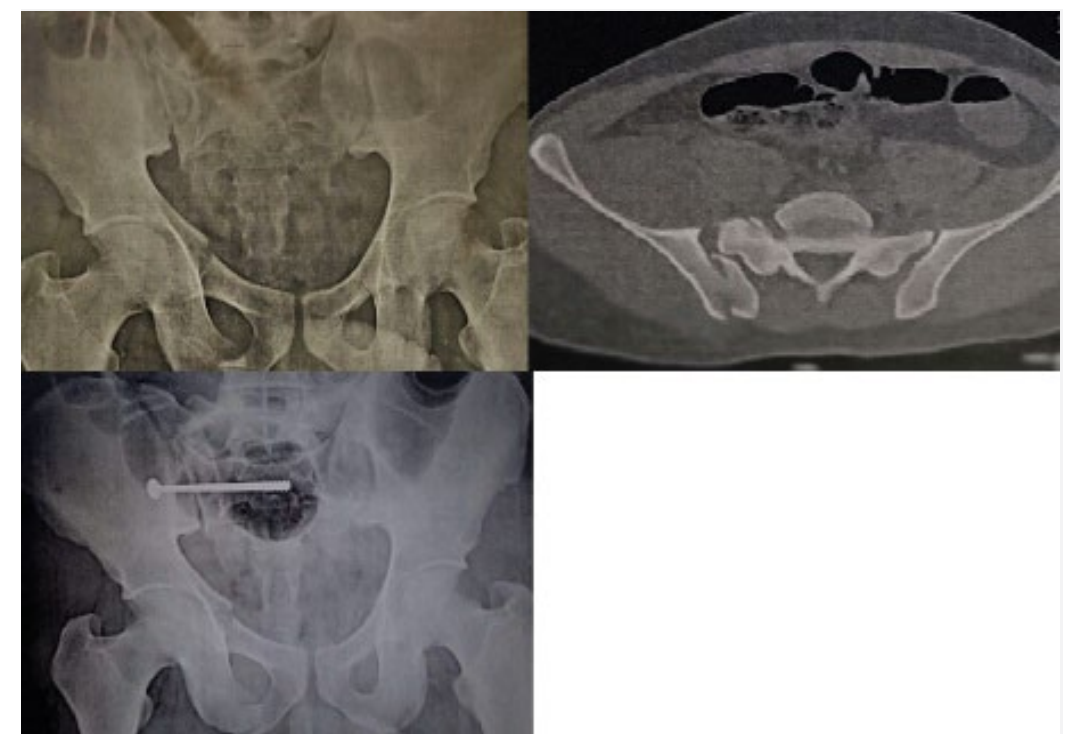

Figure 2 A 30 years old male who suffered a road traffic accident and sustained crescent type II fracture was treated with an iliosacral screw.

American Research Journal of Orthopedics and Traumatology (ARJOT) 


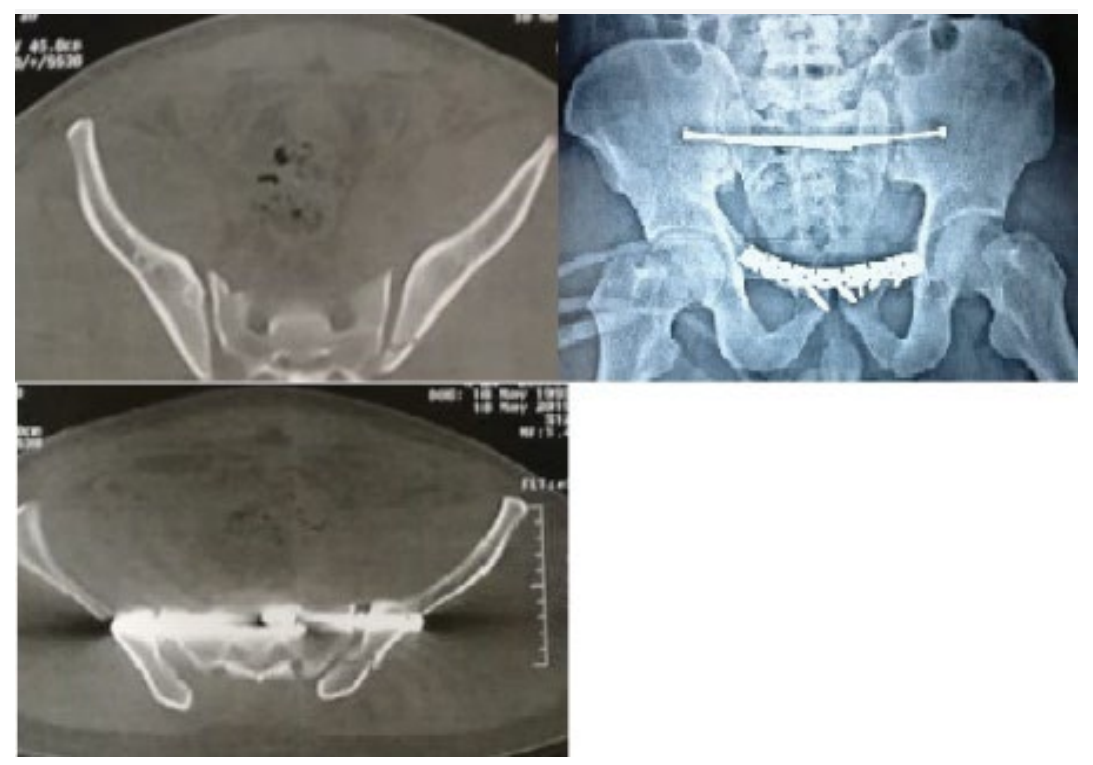

Figure 3 A 28 years old male suffered a motor car accident and sustained lt crescent type III fracture and rt SI disruption was treated with bilateral iliosacral screws and anterior plating.

\section{PATIENTS AND METHODS}

This prospective study was carried on orthopedic department of Zagazig University Hospitals aiming at assessing the results and functional scores of 30 patients [22 (73.3\%) male patients and 8 (26.7\%) female patients]. The mean age was 41.3 years (range: $28-54$ years). The study included 30 patients who had sustained crescent fractures and had been operated upon between April 2000 and June 2010. All patients sustained high-energy trauma injuries; $24(80 \%)$ patients were victims of road traffic collisions and $6(20 \%)$ were crushed by heavy objects.

Radiological evaluation included plain anteroposterior, inlet and outlet pelvic radiographs. extent of fracture line was assessed using CT scan. According to the Young classification, 16 patients had sustained a combined mechanism of injury and 14 had LC injuries. According to the Tile classification, 19 patients had type C and 11 patients had type B. Percutaneous IS alone were used in $20(45.46 \%)$ fractures ([Figure 2] and [Figure 3]). Anterior fixation was carried out in $13(15.3 \%)$ patients: 5 aterior plates, 8 external fixators.

Day's classification was used. No fractures were classified as Day I was included, $12(40 \%)$ fractures as Day II, and $18(60 \%)$ fractures as Day III.The mean follow-up period was 14 months (range: 12-21 months).

Closed reduction and percutaneous fixation using IS in cases of Day type II and Day type III ([Figure 2] and [Figure 3]). Intraoperatively, there was no significant blood loss during IS insertion. The average operative time for IS screw insertion was $37 \mathrm{~min}$; range: $25 \mathrm{~min}$ to $56 \mathrm{~min}$. Closed reduction methods included reduction of fracture rotation by Schanz screw in the ilium, and manual rotation of freely draped limb. Reduction and fixation of anterior ring fracture by anterior reconstruction or external fixator in AIIS was done in some patients.

Serial evaluations were done clinically and radiologically. Radiographic assessment was done using plain anteroposterior, inlet and outlet views included state of reduction and evidence of union. CT scan was done if there was doubt about union. Postoperative evaluation included also limb length discrepancy, state of wound, neurologic injury and any other complication. Patients were instructed to non weight-bearing for at least three weeks, mobilizing non-weight-bearing 
the other leg in the following three weeks, partial weight-bearing had started eight weeks postoperative, full weightbearing had started three months postoperative. The Majeed scoring was used for functional evaluation of the patients.

\section{RESULTS}

Intraoperatively, there was no significant blood loss in cases treated with IS The operative time was shorter for cases treated with IS (37 min; range: $25-56 \mathrm{~min}$ ). The clinical results were good in all cases: there were no wound complications, neurological complications, or residual rotational deformity of the limb. The healing rate was $100 \%$. The Majeed score was used for functional evaluation; Mean score of the 30 cases was 87 points (55-100 points); 20 (66.5\%) patients had greater than 85 points (excellent), 9 (30\%) patients had 65-84 points (good), and one (5.5\%) patients 52 and 64 points (poor).

\section{DISCUSSION}

Crescent fractures are uncommon subtype of LC fractures and are rotationally unstable. They may have some limited vertical instability; however, in contrary to Tile type $\mathrm{C}$ fractures, the sacrotuberous and sacrospinous ligaments, which remain intact, limit vertical displacement [4,6].

Crescent fractures need anatomic reduction to retain joint congruity to avoid posttraumatic arthritis. Conservative management of crescent fractures is associated with inability to perform heavy manual work and persistent posttraumatic arthritic pain [7].

The mainl goal of surgical management is accurate and stable reduction of the joint. Closed reduction and percutaneous fixation by IS was used in cases classified as Day II and III in which entry of screw remained intact and there was part of outer table of ilium at site of screw insertion sufficient to allow wire placement and insertion of screw head and washer without adding risk of comminuting the fragment. This was based on the study by Day et al. and Giannoudis $e t$ $a l$. Skeletal traction through proximal tibia applies traction with hip flexed on a table, allowing reducing both vertical and posterior displacement. Internal rotation deformity can be corrected by a percutaneous Schanz screw in anterior iliac crest or AIIS [3,8].

Starr et al. treated 27 patients with crescent fracture by closed reduction. All were followed up clinically until fracture united, except two patients were lost in early follow-up. Of 27, 16 (59\%) returned to work. All patients were ambulatory with no assistive devices, except for an 89 years old patient who used a walker. One patient had occasional hardware pain associated with weather changes and underwent hardware removal. All patients achieved fracture union [9].

Shui et al. performed a retrospective study of 117 fracture patients and concluded that functional outcome was better in patients underwent closed reduction and percutaneous screw fixation than those underwent ORIF $(\mathrm{P}<0.01)$ [10].

Khaled et al. treated 66 patients with LC fractures by percutaneous iliosacral screw in 20 fractures, plates and screws in 40 fractures, combining both in four fractures, and added LC screws in two of the cases. Most type I fractures were fixed by ORIF using plates and screws, most of the type II and III fractures were stabilized with iliosacral screw fixation percutaneously. The clinical results were good in all patients and pain-free with movement. Radiographic union was noted in $100 \%$ of Khaled's cases [11].

Another study included 43 patients who suffered from crescent fractures (44 fractures). Percutaneous iliosacral screw alone were used in 20 fractures, plates alone were used in 22 fractures, and both were used in two fractures. The operative duration was shorter for iliosacral screws (40 minutes; range: 30 to 60 minutes) than that for plate fixation (100 minutes; range: 60 to 150 minutes). The difference was statistically significant $(\mathrm{P}<0.001)$. The clinical results were good in all cases, and there were no wound complication, neurological complication, nor residual rotational deformity. The healing rate was $100 \%$ [12].

American Research Journal of Orthopedics and Traumatology 


\section{CONCLUSION}

Percutaneous IS fixation is a good option for types II and III crescent fractures, with advantages of closed reduction regarding minimal blood loss as incision is small, short operative time and soft tissue healing and stiff adequate fixation. The functional outcome of the cases fixed with IS was better.

\section{REFERENCES}

1. Borrelli J, Koval KJ, Helfet DL. The crescent fracture: a posterior fracture dislocation of the sacroiliac joint. J Orthop Trauma 1996;10:165-70.

2. Dalal SA, Burgess AR, Young JW, et al. Pelvic fracture in multiple trauma: classification by mechanism is key to pattern of organ injury, resuscitative requirements and outcome. J Trauma 1989;29:981-1000

3. Day AC, Kinmont C, Bircher MD, Kumar S. Crescent fracture-dislocation of the sacroiliac joint a functional classification. J Bone Joint Surg [Br] 2007; 89-B:651-658.

4. Tile M. Fractures of the pelvis and acetabulum. 3rd ed. Baltimore: Williams \& Wilkins; 2003. 3-21, 32-45, 116-128, 153-161.

5. Ricón Recarey FJ, Cano Luis P, Sánchez Gómez P, Fuentes Díaz A. Treatment of iliosacral joint fracture dislocations by means of an anterior extraperitoneal approach. Rev Esp Cir Ortop Traumatol 2009; 53:185-191.

6. Borrelli J Jr, Koval KJ, Helfet DL. Operative stabilization of fracture dislocations of the sacroiliac joint. Clin Orthop 1996; 329:141-146.

7. Probe, Robert A. "Stabilization of posterior pelvic injury." Operative Techniques in Orthopaedics 9.31999 ; 161176?

8. Giannoudis PV, Tzioupis CC, Pape H-C, Roberts CS. Percutaneous fixation of the pelvic ring: an update. J Bone Joint Surg Br 2007; 89-B:145-154.

9. STARR, Adam J., et al. Percutaneous screw fixation of fractures of the iliac wing and fracture-dislocations of the sacro-iliac joint (OTA Types 61-B2. 2 and 61-B2. 3, or Young-Burgess "lateral compression type II" pelvic fractures). Journal of orthopaedic trauma 2002; 16.2: 116-123.

10. SHUI, Xiaolong, et al. Percutaneous screw fixation of crescent fracture-dislocation of the sacroiliac joint. Orthopedics 2015; 38.11: e976-e982.

11. KHALED, SHERIF AHMED; EL-KARIM, M. M.; EL-AZEEM, A. H. Crescent fracture-dislocation of the sacroiliac joint: use of iliosacral screws. Med J Cairo Univ 2017; 85: 1815-1819.

12. KHALED, Sherif A., et al. Management of crescent fracture-dislocation of the sacroiliac joint: iliosacral screws versus plate fixation. The Egyptian Orthopaedic Journal 2016; 51.3: 231

Citation: Reda H. Elkady, Hamed Abuelkhair, MD, and Sherif El-Aidy MD, "Closed Reduction and Internal Fixation of Day II and III Crescent Fractures by Iliosacral Screw". American Research Journal of Orthopedics and Traumatology, vol 5, no. 1, 2020, pp. 1-5.

Copyright (c) 2020 Reda H. Elkady, et al, This is an open access article distributed under the Creative Commons Attribution License, which permits unrestricted use, distribution, and reproduction in any medium, provided the original work is properly cited. 